\title{
INFLUÊNCIA DAS PROPRIEDADES DO AGENTE LIGANTE NO CRESCIMENTO DO GRÂNULO DA PECTINA
}

\author{
T. A. M. HIRATA ${ }^{1}$, G. C. DACANAL ${ }^{2}$ e F. C. MENEGALLI ${ }^{1}$ \\ ${ }^{1}$ Universidade Estadual de Campinas, Faculdade de Engenharia de Alimentos, Departamento de \\ Engenharia de Alimentos \\ ${ }^{2}$ Universidade de São Paulo, FZEA-USP, Pirassununga, Departamento de Engenharia de Alimentos \\ E-mail para contato: akemi@fea.unicamp.br
}

\begin{abstract}
RESUMO - O objetivo deste trabalho foi comparar os grânulos de pectina obtidos pela aglomeração usando soluções aquosas de goma arábica e sacarose e tentar relacionar as propriedades dos agentes ligantes com o crescimento do grânulo. A matéria-prima utilizada foi a pectina de alto grau de metoxilação. Soluções aquosas de sacarose e de goma arábica foram usadas como agentes ligantes. Os ensaios foram realizados em um leito fluidizado pulsado. Os resultados indicaram que a viscosidade mais elevada levou a formação de grânulos maiores. A distribuição de tamanho para a pectina aglomerada com suspensão de goma arábica mostrou diâmetros acima de 513 $\mu \mathrm{m}$, enquanto a fração de partículas menores foi maior para a solução de sacarose. Analisando-se as microscopias eletrônicas de varredura notou-se que as ligações partícula-partícula se mostraram frágeis e com rachaduras para as soluções de sacarose. Este comportamento evidenciou que soluções mais viscosas produzem grânulos mais fortes.
\end{abstract}

\section{INTRODUÇÃO}

Produtos alimentares são frequentemente desenvolvidos na forma de pó por uma série de razões, incluindo uma longa vida de prateleira, facilidade de transporte e no uso final do consumidor. Contudo, muitos problemas relacionados a qualidade física do pós são relatados, principalmente a formação de grumos durante sua reidratação, o que pode causar problemas ao consumo final, como a aceitação do produto. E a nível industrial pode causar entupimento de tubulações devido a dificuldade no escoamento do pó e impedir uma mistura homogênea durante o preparo de formulações em pó. Por isso a importância do processo de aglomeração em melhorar as propriedades de instantaneização dos materiais particulados.

A aglomeração em leito fluidizado consiste em aspergir um líquido (água ou solução aquosa de ligante) no leito de partículas sólidas fluidizadas por um ar quente. As gotas líquidas colidem com as partículas em movimento criando zonas pegajosas nas suas superfícies, ou umedecendo (partículas solúveis em água) ou se depositando na superfície da partícula (partículas não solúveis). O aglomerado se forma quando essas partículas pegajosas colidem e formam pontes líquidas ou viscosas que se secam e se consolidam pela fluidização de ar quente. A repetição desses eventos (aspersão de 
ligante, umedecimento, colisão, adesão e secagem) permite o crescimento progressivo do grânulo.

O objetivo deste capítulo foi comparar os grânulos de pectina obtidos pelo processo de aglomeração utilizando soluções aquosas de goma arábica e sacarose e tentar relacionar as diferentes propriedades dos agentes ligantes, como: viscosidade e ângulo de contato, com o crescimento dos grânulos.

\section{MATERIAIS}

Pectina de alto grau de metoxilação (Genu pectin type B rapid set-Z CP Kelco), extraída da casca de frutas cítricas foi utilizada neste estudo. Esta pectina, na forma de pó, possui uma coloração creme, com diâmetro médio de partícula de $131 \mu \mathrm{m}$, densidade do leito de partículas de $0,568 \mathrm{~g} \mathrm{~cm}^{-3}$, e densidade do leito de partículas compactado de $0,760 \mathrm{~g} \mathrm{~cm}^{-3}$. Suspensões aquosas de goma arábica e soluções aquosas de sacarose foram usadas como agente ligante.

A goma arábica em pó (Labsynth) utilizada no preparo das suspensões era um pó fino levemente amarelado, inodoro e com solubilidade em água de aproximadamente $500 \mathrm{~g} / \mathrm{l}$. Sacarose P.A. (Labsynth) foi utilizada no preparo das soluções aquosas de sacarose.

\section{MÉTODOS}

\subsection{Leito Fluidizado Pulsado}

Os ensaios foram realizados em um leito fluidizado pulsado, detalhes a respeito deste equipamento são dados por Dacanal (2009).

Os parâmetros fixos do processo estão apresentados na Tabela 1. Para os ensaios realizados com suspensão de goma arábica a temperatura do ar fluidizante $\left(T_{f}\right)$ foi de $82,5{ }^{\circ} \mathrm{C}$ e concentração de ligante $\left(C_{\text {lig }}\right)$ igual a $15 \%$. Para os ensaios realizados com sacarose esses parâmetros foram fixados em $75^{\circ} \mathrm{C}$ e $20 \%$. A escolha desses valores foi baseada em testes preliminares a fim de se obter o melhor produto aglomerado com suspensão de goma arábica e com solução de sacarose.

Tabela 1 - Parâmetros fixos utilizados no processo de aglomeração de pectina em pó.

\begin{tabular}{|c|c|}
\hline Parâmetros & Níveis \\
\hline Tempo de Processo & 30 minutos \\
\hline Pressão de atomização & $0,5 \mathrm{bar}$ \\
\hline Frequência de pulsação & $600 \mathrm{rpm}$ \\
\hline Altura do bico aspersor em relação a base do leito & $300 \mathrm{~mm}$ \\
\hline Massa de amostra & $0,150 \mathrm{~kg}$ \\
\hline Velocidade do ar fluidizante $\left(V_{f}\right)$ & $0,72 \mathrm{~m} / \mathrm{s}$ \\
\hline Vazão de ligante $\left(Q_{\text {lig }}\right)$ & $1,6 \mathrm{~mL} / \mathrm{min}$ \\
\hline
\end{tabular}




\section{9 a 22 de outubro de 2014 \\ Florianópolis/SC}

O diâmetro médio e a distribuição de tamanho das partículas foram feitas por peneiramento onde $10 \mathrm{~g}$ de amostra foram colocados em um série de 12 peneiras ( $8 \mathrm{~cm}$ de diâmetro) com aberturas entre 38 e $2000 \mu \mathrm{m}$, de acordo com progressão geométrica $2^{1 / 2}$. O diâmetro médio da partícula foi calculado de acordo com a Equação 1, em que, dpm é o diâmetro médio das partículas, xi a fração mássica e dpi o diâmetro médio no intervalo i e n o número de intervalos.

$d p_{m}=\sum_{i=1}^{n} x_{i} d p_{i}$

\subsection{Reologia dos agentes ligantes}

As curvas de escoamento das suspensões de goma arábica (5, 10, 15 e 20\% de concentração) foram determinadas em um intervalo de taxa de deformação entre 0 e aproximadamente $300 \mathrm{~s}^{-1}$ nas temperaturas de $25,45,60,70$ e $80{ }^{\circ} \mathrm{C}$ em um reômetro AR1500 (TA Instruments) utilizando uma geometria cone-placa de aço inoxidável de $60 \mathrm{~mm}$ de diâmetro $\left(2^{\circ}\right)$. Todas as medidas foram realizadas em triplicata.

\section{2. Ângulo de contato}

Os ângulos de contato, entre os agentes ligantes e a pectina em pó, foram determinados em um tensiômetro de gota pendente Tracker-S (Teclis, França). A pectina em pó foi colocada sobre uma lâmina de vidro coberta com uma fita adesiva dupla face. As partículas que não se prenderam a fita foram removidas. Então, uma gota de solução ligante foi depositada sobre a lâmina contendo a pectina em pó e as medidas foram feitas durante 60 segundos a temperatura de $25^{\circ} \mathrm{C}$.

Esta metodologia foi escolhida de acordo com o estudo de Nowak et al (2013), onde foi comparado diferentes métodos para se medir o ângulo de contato usando-se os seguintes pós: óxido de alumínio $\left(\mathrm{Al}_{2} \mathrm{O}_{3}\right)$, dióxido de zircônio $\left(\mathrm{ZrO}_{2}\right)$, dióxido de silício $\left(\mathrm{SiO}_{2}\right)$ e dióxido de titânio $\left(\mathrm{TiO}_{2}\right)$. Os autores concluíram que os dados fornecidos pelo método utilizando lâminas cobertas com fita adesiva foram mais consistentes com as observações para todos os pós investigados e também apresentaram boa reprodutibilidade dos resultados.

\subsection{Microscopia Eletrônica de Varredura (MEV)}

Foi feito um recobrimento metálico nas amostras com uso do equipamento Sputter Coater POLARON, Modelo SC7620, Marca VG Microtech (Inglaterra). Para obtenção das imagens foi utilizado o equipamento Microscópio Eletrônico de Varredura (MEV) com Detector de Energia Dispersiva de Raios-X (EDX), Marca MEV/EDX: LEO Electron Microscopy/Oxford (Inglaterra), Modelo MEV: Leo 440i Modelo EDX: 6070, do Laboratório de Recursos Analíticos e de Calibração (LRAC) da Faculdade de Engenharia Química da Universidade Estadual de Campinas. A faixa de trabalho do equipamento é de 30 a 300.000 vezes de aumento, resolução: $10 \mathrm{~nm}$ (de fábrica), tamanho de amostras: até 2,5 x 2,5 x 0,7 cm, distância de trabalho (foco): de 3 a $50 \mathrm{~mm}$, energia do feixe de elétrons (tensão de aceleração): $300 \mathrm{~V}$ a $30 \mathrm{kV}$, corrente do feixe de elétrons: 1 pA a $1 \mathrm{~mA}$. 


\section{RESULTADOS E DISCUSSÕES}

Analisando-se as curvas de escoamento para as suspensões de goma arábica (Figura 1) observou-se que quando a taxa de deformação é alta, o valor da viscosidade aparente tende a ficar constante, no entanto a taxas de deformação baixas apresenta um comportamento não newtoniano nas concentrações de 5, 10, 15 e 20\%. Estes resultados foram diferentes do observado por alguns autores que afirmaram que as suspensões de goma arábica apresentam valores de viscosidade elevados somente a altas concentrações (> 30\%) devido a sua estrutura altamente ramificada e apresentam comportamento newtoniano mesmo a concentrações a 40\% (WHISTLER e BEMILLER, 1993; CUI, 2005). Os valores experimentais foram ajustados para o modelo Herschel-Bulkley, considerado um fluido lei da potência com tensão residual.
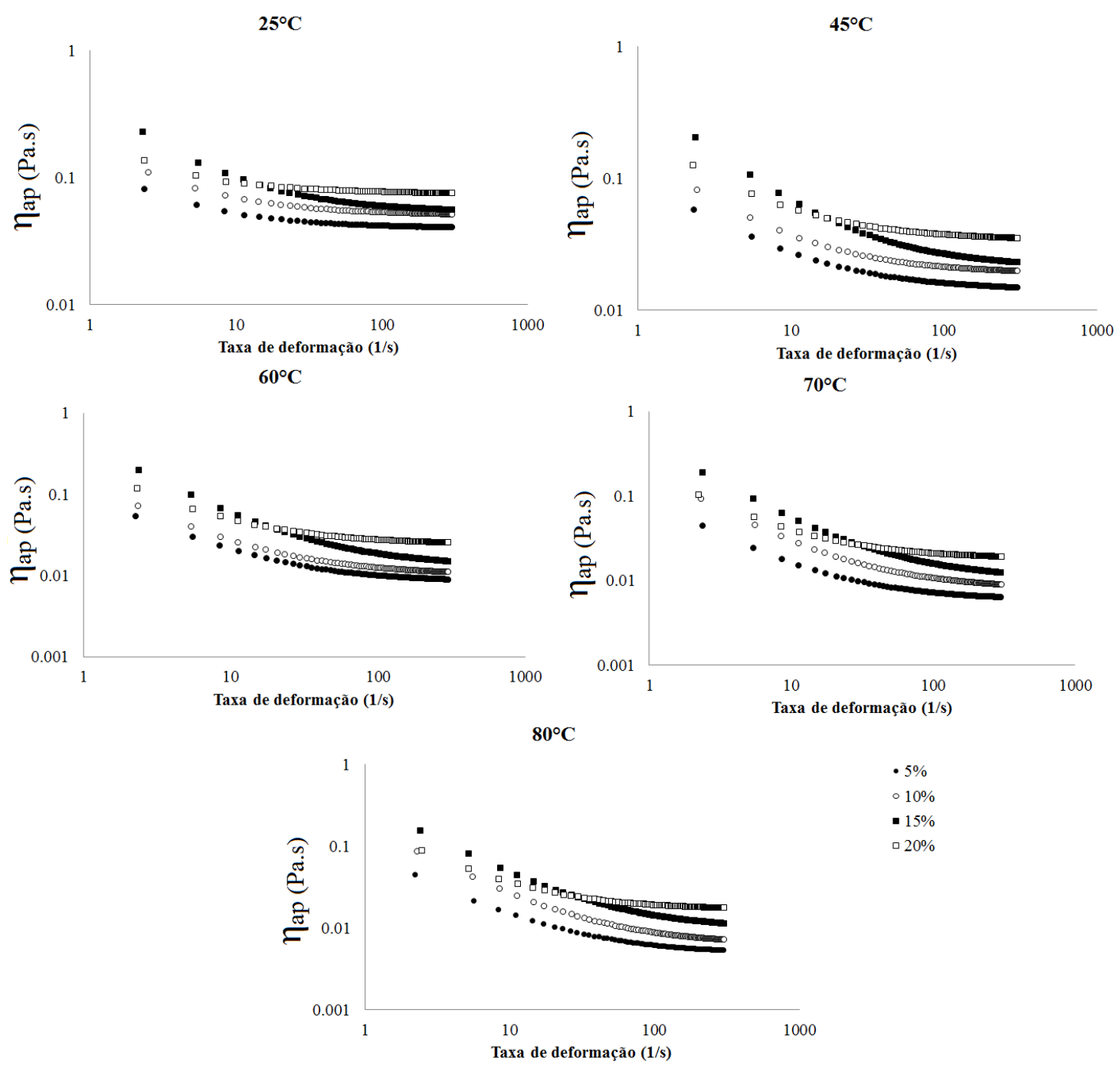

Figura 1 - Viscosidade aparente das soluções aquosas de goma arábica nas temperaturas de 25 ${ }^{\circ} \mathrm{C}, 45^{\circ} \mathrm{C}, 60{ }^{\circ} \mathrm{C}, 70^{\circ} \mathrm{C}$ e $80{ }^{\circ} \mathrm{C}$. 
A viscosidade aparente foi calculada para uma taxa de deformação de $100 \mathrm{~s}^{-1}$, pois as curvas mostram que para valores de taxas de deformação superiores a $100 \mathrm{~s}^{-1}$ a viscosidade aparente tende a se tornar constante e, mesmo a baixos valores de taxa de deformação, a viscosidade aparente da goma arábica é superior a viscosidade da solução de sacarose (Tabela 2).

As soluções de sacarose pura apresentam comportamento newtoniano.

Tabela 2 - Viscosidade da suspensão de goma arábica e solução sacarose a diferentes temperaturas.

\begin{tabular}{|c|c|c|c|}
\hline Temperatura & Goma arábica $\left(\eta_{\text {ap }}\right)$ & Temperatura & Sacarose $(\eta)^{*}$ \\
\hline $25^{\circ} \mathrm{C}$ & $60 \mathrm{mPa} . \mathrm{s}$ & $30^{\circ} \mathrm{C}$ & $1,49 \mathrm{mPa} . \mathrm{s}$ \\
\hline $45^{\circ} \mathrm{C}$ & $27 \mathrm{mPa} . \mathrm{s}$ & $40^{\circ} \mathrm{C}$ & $1,18 \mathrm{mPa} . \mathrm{s}$ \\
\hline $60^{\circ} \mathrm{C}$ & $19 \mathrm{mPa} . \mathrm{s}$ & $60^{\circ} \mathrm{C}$ & $0,81 \mathrm{mPa} . \mathrm{s}$ \\
\hline $70^{\circ} \mathrm{C}$ & $16 \mathrm{mPa} . \mathrm{s}$ & $70^{\circ} \mathrm{C}$ & $0,68 \mathrm{mPa} . \mathrm{s}$ \\
\hline $80^{\circ} \mathrm{C}$ & $15 \mathrm{mPa} . \mathrm{s}$ & $80^{\circ} \mathrm{C}$ & $0,68 \mathrm{mPa} . \mathrm{s}$ \\
\hline
\end{tabular}

*Fonte: MATHLOUTHI e REISER, 1995.

O ângulo de contato de um líquido em um substrato é um bom indicador da hidrofobicidade ou hidrofilicidade relativa do substrato. O conhecimento do comportamento da molhabilidade de um agente ligante no pó a ser aglomerado é um pré-requisito para entender e controlar melhor o processo de granulação quando há a formação de pontes líquidas entre as partículas sólidas (DAHLBERG et al, 2008; SUSANA et al, 2012).

Quando a gota de líquido é totalmente absorvida pelo substrato seu ângulo de contato é $0^{\circ}$. Reciprocamente, se a gota de líquido é difícil de ser absorvida, o líquido não irá se espalhar facilmente pelo substrato e assim irá repousar sobre a superfície formando ângulos maiores que $90^{\circ}$ (BEATTY e SMITH, 2010).

As fotografias contendo as medidas dos ângulos de contato para a suspensão de goma arábica e de sacarose são apresentadas pela Figura 1. Tanto para a suspensão de goma arábica quanto para a solução de sacarose, os ângulos foram menores que $90^{\circ}$, mostrando que essas duas soluções apresentam boas propriedades de molhabilidade quando em contato com a pectina em pó. 
(a)

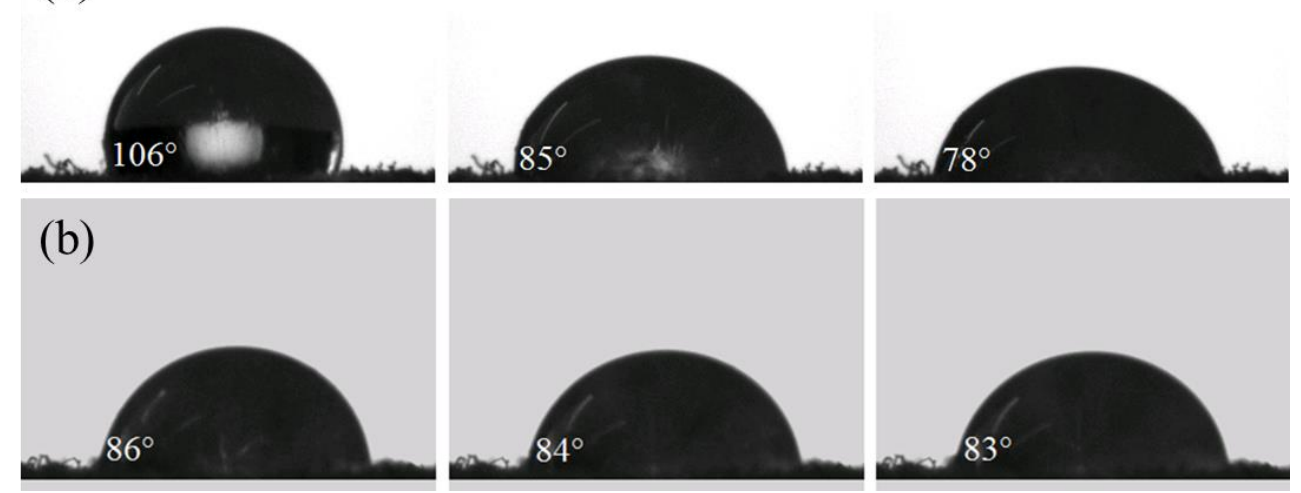

Figura 1 - Ângulo de contato entre a superfície de pectina em pó e suspensão de goma arábica $15 \%$ (a) e solução de sacarose $20 \%$ (b).

O aumento do tamanho da partícula foi maior quando o ângulo de contato entre as soluções ligantes e a pectina em pó foi maior. Os pequenos capilares dentro das partículas porosas drenam o líquido para o interior deixando menos líquido disponível na superfície para originar as pontes líquidas necessárias para adesão partícula-partícula (HAPGOOD et al, 2007). E, de acordo com Pont et al (2001), para partículas totalmente hidrofóbicas, a adesão se torna difícil. Neste caso, a solução ligante recobre a partícula e seca. A fraca adesão entre o filme de ligante formado na superfície das partículas, e o aumento das forças de atrito devido ao movimento dentro do leito, se fragmenta e é elutriado pelo gás fluidizante.

Embora os melhores valores de diâmetro médio da partícula obtidos para os ensaios contendo sacarose e goma arábica não tenham sido realizados sob as mesmas condições de processo, diferindo nos parâmetros temperatura de fluidização do ar e concentração de ligante, de acordo com trabalhos anteriores a resposta diâmetro médio não foi influenciada pela variável $T_{f}$, deste modo podemos fazer uma análise qualitativa em relação a viscosidade e ângulo de contato.

Analisando-se apenas as distribuições de tamanho referentes aos melhores diâmetros médios alcançados com a aglomeração de pectina com solução de sacarose e suspensão de goma arábica vê-se que a viscosidade maior levou a formação de grânulos maiores (Figura 2), o que também foi observado por Pont et al (2001). Na distribuição de tamanho dos grânulos obtidos utilizando suspensão de goma arábica na aglomeração as frações dos diâmetros acima de $513 \mu \mathrm{m}$ foram maiores enquanto que na distribuição de tamanho utilizando solução de sacarose a fração de partículas menores foi maior. A aglomeração com solução de sacarose pode ter gerado grânulos com pontes de ligação mais fracas proporcionando a ruptura dessas pontes.

Reynolds et al (2005) revisaram diversos trabalhos que estudaram o processo de quebra do grânulo e muitos autores relataram que a viscosidade do ligante afeta a resistência mecânica do grânulo onde viscosidades menores tornaram os grânulos mais susceptíveis a fragmentação durante o processo de granulação e viscosidades maiores resultaram em grânulos maiores. 
O mecanismo de quebra no processo de granulação influência na formação de um produto de qualidade bem como nos processos subsequentes como transporte, manuseio e seu uso final.

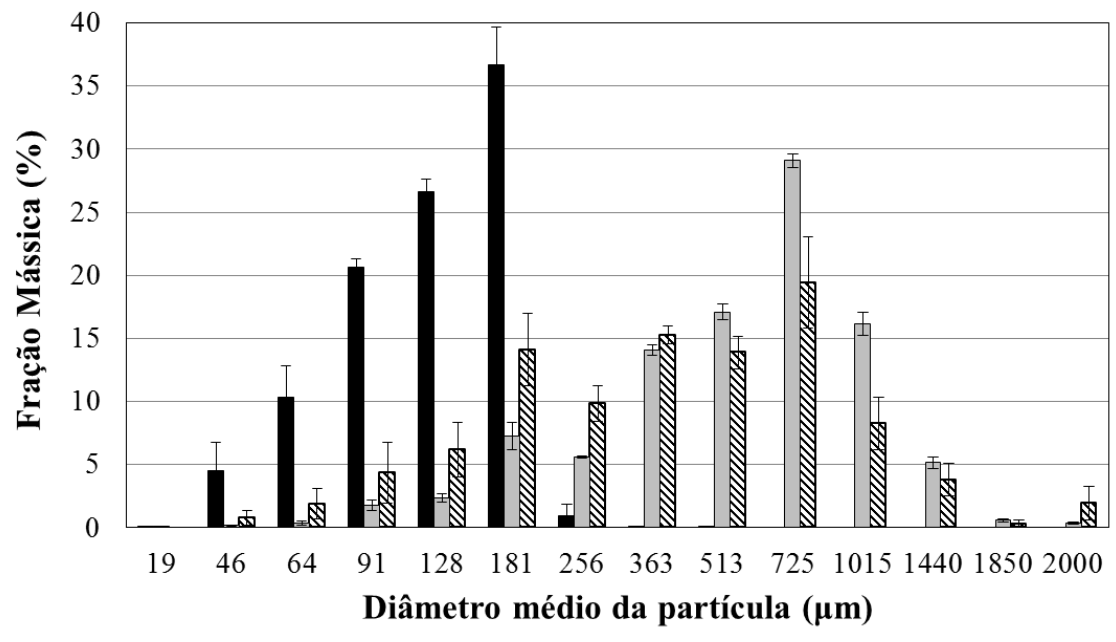

$\mathbb{\$}$ Sacarose $\square$ Goma arábica $\quad$ Matéria-prima

Figura 2 - Distribuição de tamanho da matéria-prima e pectina aglomerada com soluções aquosas de sacarose e goma arábica.

Com auxílio das microscopias eletrônicas de varredura (Figura 3), pode-se observar que para a goma arábica a solução ligante forma uma ponte sólida mais extensa e definida do que a solução ligante de sacarose que apresenta rachaduras em sua superfície reforçando o que foi dito anteriormente, soluções mais viscosas formam grânulos mais fortes e maiores o que evita a sua quebra no interior do leito fluidizado durante o processo de aglomeração.

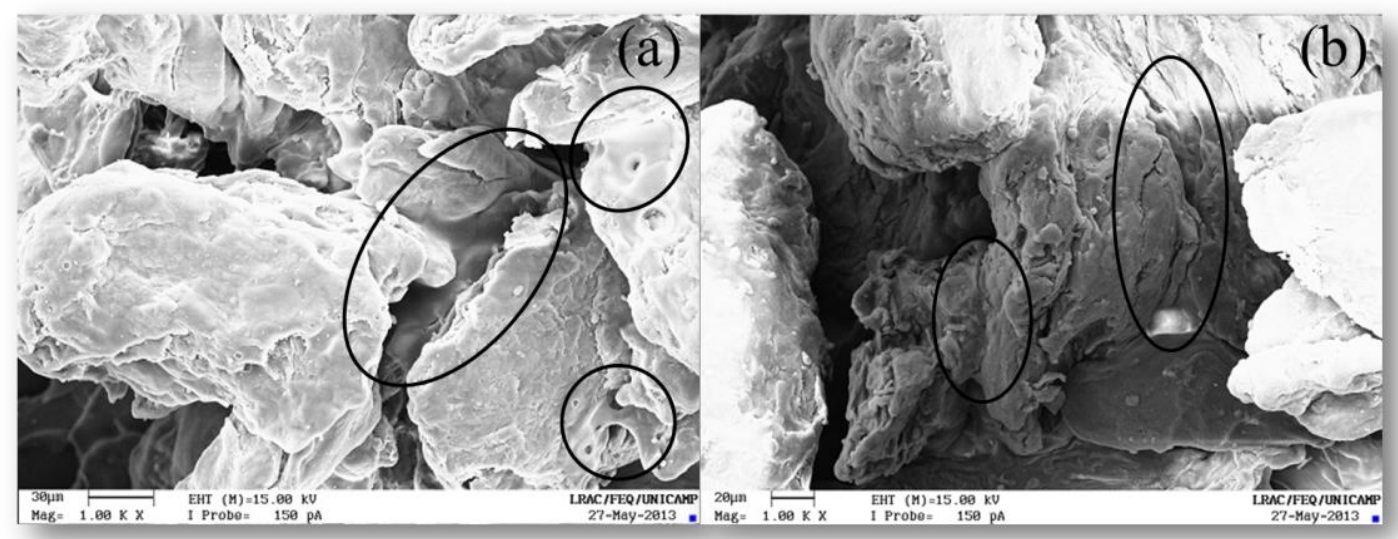

Figura 3 - Microscopia eletrônica de varredura para a pectina aglomerada com suspensão de goma arábica $15 \%$ (a) e solução de sacarose $20 \%$ (b), aumentos de 1000x 


\section{CONCLUSÕES}

Verificando-se o ângulo de contato entre o agente ligante e a pectina em pó, chegou-se a conclusão de que, neste caso, uma menor afinidade, ou seja, ângulos de contato moderados entre ligante-partícula e soluções mais viscosas foram melhores para o processo de granulação, pois proporcionaram a formação de pontes líquidas necessárias à adesão entre as partículas. E, analisandose as microscopias eletrônicas de varredura dos grânulos gerados com a suspensão de goma arábica e com a solução de sacarose notou-se que as ligações partícula-partícula apresentaram rachaduras nos grânulos obtidos no processo de aglomeração utilizando a solução de sacarose evidenciando o fato de que soluções mais viscosas produzem pontes de ligação mais definidas e extensas.

\section{REFERENCIAS}

DACANAL, G. C.; MENEGALli, F. C. Experimental study and optimization of the agglomeration of acerola powder in a conical fluid bed. Powder Technol, v. 188, p. 187-194, 2009.

NOWAK, E.; COMBES, G.; STITT, E. H.; PACEK, A. W. A comparison of contact angle measurement techniques applied to highly porous catalyst supports. Powder Technol, v. 233, p. 52-64, 2013.

WHISTLER, R. L.; BEMILLER, J. N. Industrial gums: polysaccharides and their derivatives. 3. ed. San Diego: Academic Press, 1993. 642p.

CUI, S. W. Food carbohydrates: chemistry, physical properties and applications. Boca Raton: Taylor and Francis, 2005. 418p.

DAHLBERG, C.; MILLQVIST-FUREBY, A.; SCHULEIT, M. Surface composition and contact angle relationships for differently prepared solid dispersions. Eur J Pharm Biopharm, v. 70, p. 478-485, 2008.

SUSANA, L.; CAMPACI, F.; SANTOMASO, A. C. Wettability of mineral and metallic powders: Applicability and limitations of sessile drop method and Washburn's technique. Powder technol, v. 226, p. 68-77, 2012.

BEATTY, S. M.; SMITH, J.E. Fractional wettability and contact angle dynamics in burned water repellent soils. J Hydrol, v. 391, p. 97-108, 2010.

HAPGOOD, K. P.; IVESON, S. M.; LITSTER, J. D.; LIU, L.X. Granulation rate process. In: Hand Powder Technol, v. 11, p. 897-977, 2007.

PONT, V.; SALEH, K.; STEINMETZ, D.; HÉMATI, M. Influence of the physicochemical properties on the growth of solid particles by granulation in fluidized bed. Powder Technol, v. 120, p. 97-104, 2001.

REYNOLDS, G. K.; FU, J. S.; CHEONG, Y. S.; HOUNSLOW, M. J.; SALMAN, A. D. Breakage in granulation: A Review. Chem Eng Sci, v. 60, p. 3969-3992, 2005. 